\title{
JOGO DE EMPRESAS INTERDISCIPLINAR: ELABORAÇÃO E TESTE
}

\author{
INTERDISCIPLINARY BUSINESS GAME: DEVELOPMENT ANDTEST \\ DOI: http://dx.doi.org/10.12712/rpca.v6i2.127
}

\author{
Leonardo de Oliveira Santoro \\ Faculdade Moraes Junior - Mackenzie Rio \\ lsantoro@pensarmais.com.br
}

\section{Marco Aurélio Carino Bouzada}

Universidade Estácio de Sá

marco.bouzada@estacio.br

\section{Resumo}

Este artigo buscou responder como deve ser e quais conceitos deve-se trabalhar em um jogo de empresa interdisciplinar que vise dar algum tipo de experiência vivencial a estudantes no final de seus cursos superiores, para que os mesmos não cheguem ao mercado de trabalho apenas com a visão de sua área de formação e sem nenhuma noção de quais resultados suas decisões podem gerar no dia-adia das empresas. Através desse estudo pretendeu-se verificar duas hipóteses: se a assimilação dos conceitos para os participantes do jogo foi superior à dos não participantes (H1); e se os participantes com melhores resultados no jogo também foram os que tiveram melhor assimilação dos conceitos (H2). Detalhes sobre a construção do jogo, seus conceitos e variáveis são apresentados, assim como a metodologia de coleta (através da aplicação-teste do jogo e de uma prova interdisciplinar junto a uma turma de graduação) e tratamento dos dados e as limitações da pesquisa. Após realizado um teste Mann-Whitney de comparação de duas medianas, a H1 foi confirmada. Quanto à H2, uma análise de correlação levou à sua rejeição. Com os resultados obtidos, o que se pode concluir é que o importante para o aprendizado é a participação no jogo e não o resultado em si. Essa participação, e não o resultado, é que faz com que o aluno tenha uma maior assimilação dos conceitos propostos.

Palavras-chave: Jogos de Empresas. Aprendizado. Teste

\begin{abstract}
This article sought to answer how it should be and what concepts should be worked in an interdisciplinary business game aimed at giving some sort of practical experience to students at the end of their graduation courses, so that they do not reach their jobs only with their training area vision and without any notion of what results their decisions can generate in business routine. This study sought to verify two hypotheses: if the assimilation of concepts for the game participants was higher than for non-participants (H1); and if participants with better results in the game also were the ones that had better concepts assimilation (H2). Details about the game construction, its concepts and variables are presented, as well as the way data was collected (through the game test-application and a interdisciplinary teste applied to a graduation class) and processed and the research limitations. After a Mann-Whitney test for two medians, $\mathrm{H} 1$ was confirmed. As for $\mathrm{H} 2$, a correlation analysis led to its rejection. With the results obtained, what can be concluded is that the participation in the game is important for learning and not the result itself. Such participation, and not the result, does cause a greater concepts assimilation for the student.
\end{abstract}

Keywords: Business Games. Learning. Test. 


\section{Introdução}

Ao longo dos anos o processo de ensino-aprendizagem teve como principal forma de transmissão do conhecimento a aula expositiva. Por este método de ensino, o assunto é transmitido pela exposição contínua de um professor e, na grande maioria das vezes, não há interação direta com os alunos, pois muitos limitam-se a ouvir e anotar algumas questões que julgam pertinentes. A metodologia da aula expositiva ainda é utilizada na grande maioria das matérias lecionadas nos cursos superiores em nosso país e recebe muitas criticas por parte de educadores por não incentivar a participação ativa dos alunos, através de discussão.

Segundo Muritiba, Sauaia e Muritiba (2006), embora se verifique um efetivo aumento de produtividade do sistema educacional, os dados ainda mostram que uma parcela importante de 35\% dos alunos ingressantes não conclui o curso superior. Os autores concluem que o elevado índice de evasão dos estudantes reforça a importância de se pesquisar métodos educacionais.

Fazer com que o estudante se mantenha motivado é essencial para que o processo educacional tenha resultado. Para tanto, o professor precisa lidar com alguns desafios como salas de aula lotadas, alunos com dificuldade de aprendizado ou que chegam cansados para a aula após um dia de trabalho. 0 objetivo do professor deveria ser promover 0 desenvolvimento intelectual dos alunos, o que os ajudaria a tomar melhores decisões quando fossem aplicar seus conhecimentos.

Existem diversos métodos de ensino que um professor pode usar em sala de aula: aulas expositivas, exercícios, jogos, estudos de caso, discussões em grupos, entre outros. A escolha do método deve ser adequada ao conteúdo que será apresentado, ao tipo de matéria que será lecionada, ao estilo do professor e ao tipo de aluno. A escolha do método mais adequado trará os melhores resultados para o aprendizado dos alunos.

Um discurso que se torna cada vez mais presente dentro das instituições de ensino superior diz respeito à necessidade de se preparar os egressos para que os mesmos se tornem gestores em condições de atuar no mercado de trabalho atendendo às necessidades demandadas pelas empresas.

Rodrigues e Riscarroli (2001) garantem existir na atualidade instrumentos pedagógicos mais eficientes para a finalidade de preparar esses futuros gestores. Na visão de tais autores, jogos de empresas prestam-se especificamente para essa tarefa.

Para Rosas (2009), um importante argumento no uso de jogos de empresas é que a prática de decisões e conceitos em ambientes simulados evita prejuízos reais que incorreriam caso o aprendizado fosse feito na gestão de um negócio real.

As instituições de ensino vêm recorrendo ao uso de jogos de empresas em suas grades curriculares cada vez mais, sendo utilizados na graduação e também na pós-graduação. De acordo com Sauaia (1995), o processo de ensino-aprendizagem através da simulação empresarial baseada em jogos de empresas é muito bem aceito pelos alunos, pois proporciona aprendizagem e satisfação e, se bem explorado, representa um recurso valioso que pode muito contribuir para a educação gerencial dos egressos dos cursos de bacharelado nas áreas de gestão.

A intenção é buscar incorporar formas melhores de preparar seus estudantes para o mercado de trabalho. A formação de gestores com perfil adequado ao que as empresas necessitam faz 
com que as instituições de ensino debatam formas de relacionar teoria e prática, necessitando analisar algumas questões como a fragmentação do conhecimento, a falta de pensamento sistêmico, a pouca integração entre as áreas do conhecimento, a excessiva racionalidade em detrimento ao pensamento critico, entre outras.

Fica clara, então, a importância do treinamento desse futuro gestor, com o intuito de aproximar os conceitos aprendidos da realidade empresarial. A sugestão é o uso de jogos de empresas, onde os estudantes podem testar seus conhecimentos em um ambiente virtual, onde as falhas são admitidas e os jogadores podem aprender com seus erros, observando o reflexo de suas decisões nos resultados da empresa simulada.

Considerando o cenário apresentado, o Projeto Pedagógico dos cursos de Administração, Contabilidade e Economia da Faculdade Moraes Junior Mackenzie Rio decidiu incluir no oitavo e último módulo de suas grades curriculares a disciplina Jogos e Simulações de Negócios, buscando testar em um ambiente simulado alguns dos conhecimentos que se fazem necessários para que seus alunos atuem de forma competente no mercado detrabalho.

No entanto, alguns dos jogos de empresas disponíveis não parecem atender a essa finalidade, uma vez que não possuem todas as características interdisciplinares que se espera trabalhar, muitos deles estando focados apenas em alguma área especifica, como logística, custos ou marketing.

Desta forma, apresenta-se a problemática da pesquisa, onde se pretendeu responder como deve ser e quais conceitos deve-se trabalhar em um jogo de empresa interdisciplinar que vise dar algum tipo de experiência vivencial a estudantes no final de seus cursos superiores, para que os mesmos não cheguem ao mercado de trabalho apenas com a visão de sua área de formação e sem nenhuma noção de quais resultados suas decisões podem gerar no dia-a-dia das empresas.

O objetivo principal desta pesquisa foi desenvolver e testar um jogo de empresas para uso na disciplina Jogos e Simulações de Negócios, que fará parte da grade curricular dos cursos de Administração, Contabilidade e Economia da Faculdade Moraes Junior Mackenzie Rio, definindo quais devem ser as decisões e suas alternativas e quais devem ser as características organizacionais que permitam moldar o contexto no qual as decisões serão tomadas.

Os objetivos intermediários foram: (i) definir os conceitos, as decisões e suas alternativas e as características organizacionais que serão trabalhadas no jogo; (ii) desenvolver o modelo matemático do jogo, utilizando planilhas Excel; (iii) realizar aplicação-teste do jogo, refinando os modelos através dos feedbacks obtidos; (iv) avaliar a assimilação dos conceitos para os participantes do jogo em comparação a não participantes; e (v) medir a relação entre o desempenho das equipes no jogo e a assimilação dos conceitos dos seusintegrantes.

Através desse estudo, pretendeu-se verificar duas hipóteses: se a assimilação dos conceitos para os participantes do jogo foi superior à de quem não participou do jogo (H1); e se os participantes com melhores resultados no jogo também foram os que tiveram melhor assimilação dos conceitos (H2).

Pereira, Santos e Rech (2008), em seu estudo com egressos de cursos de graduação em Ciências Contábeis de todo o país, constataram que $69,27 \%$ dos que responderam sua pesquisa discordaram de terem recebido uma formação acadêmica que lhes propiciasse ser um profissional criativo e crítico. Segundo os autores, os dados permitem inferir que os egressos não se sentem preparados para enfrentar as necessidades do mercado de trabalho,já 
que o mesmo tem exigido profissionais com habilidades que permitam buscar soluções imediatas, a partir de uma visão multidisciplinar. Em sua pesquisa, os autores ainda puderam apurar que $89,37 \%$ dos respondentes discordaram de que sejam capazes de enfrentar problemas globais, julgando não estarem aptos para atender ao mercado de trabalho atual. Os autores concluem que os profissionais não estão sendo formados com uma visão global da realidade, sendo esta, hoje, uma necessidade do mercado globalizado.

Desta forma, a importância deste trabalho reside nos conceitos interdisciplinares trabalhados no jogo construído, uma vez boa parte dos jogos pesquisados não apresenta esta característica interdisciplinar. A ideia é que esse jogo possa servir de experiência vivencial para seus participantes, com o objetivo de que os mesmos tenham condições de avaliar os resultados de suas ações no dia-a-dia de uma organização em um ambiente simulado, sem prejuízos que poderiam vir a ter se o fizessem na vida real. Com isso, espera-se colocar no mercado de trabalho egressos bem preparados que possam atender as necessidades das empresas e da sociedade.

\section{Referencial teórico}

\section{Jogos de empresas}

A simulação da gestão empresarial, também chamada de Jogo de Negócios ou Business Game, é uma simulação do ambiente e dos cenários com os quais as empresas convivem que permite verificar, avaliar e analisar as possíveis consequências de decisões tomadas sem os prejuízos reais que as mesmas poderiam vir a causar. As decisões são tomadas pelos participantes do jogo em sucessivos períodos de tempo, que equivalem a um determinado período de operação da empresa hipotética. A cada rodada, os participantes recebem informações sobre os resultados de suas decisões anteriores e podem reorientar os destinos da empresa para os períodos subsequentes.

Em um jogo de empresas, os participantes podem desempenhar várias funções que estão presentes nas organizações como marketing, produção, recursos humanos, pesquisa e desenvolvimento, logística, contabilidade, entre outras. Eles assumem os diferentes papéis gerenciais, definindo metas e estratégias de sua organização simulada. Eles têm o controle de suas ações e acompanham os resultados produzidos por suas decisões. A experiência vivencial submete os jogadores às forças competitivas, econômicas, legais e políticas, que criam ameaças e oportunidades, orientando o comportamento empresarial simulado, tal qual ocorre com as empresas reais. Os jogos buscam simular o ambiente empresarial, colocando os jogadores em situações similares às que passam os executivos em sua rotina de trabalho. Buscam retratar de forma simplificada a realidade complexa das empresas, delimitando algumas variáveis trabalhadas e restringindo o impacto de outras no modelo. (BATISTA, 2004; FERREIRA, 2000; ROCHA, 1997; KOPITTKE, 1989; MIYASHITA, 1997; SCHAFRANSKI, 2002; ROSAS; SAUAIA, 2006)

Sauaia (1989) ressalta três objetivos gerais dos jogos de empresas, focando nos ganhos para as pessoas que participam de sua aplicação:

- Aumento do conhecimento: pela aquisição de novos conhecimentos, propiciada pela incorporação de novas informações trazidas ao contexto do jogo; pela integração de conhecimentos que passam a fazer sentido; e por meio do resgate de conhecimentos anteriormente adquiridos, cuja vivência facilita o acesso a eles; 
- Desenvolvimento de habilidades: por meio da prática gerencial repetida;

- Fixação de atitudes: através da transposição da aprendizagem propiciada pelos acontecimentos fictícios, inseridos em um cenário simulado, para o ambientereal.

Vicente (2005) diz que o objetivo de um jogo de empresa é criar um cenário predefinido, no qual os participantes serão submetidos a um ambiente simulado, onde tomarão decisões baseadas em informações que receberem. Tais simulações podem ser uma poderosa ferramenta de ensino, pois estimulam os alunos a pensarem em todas as variáveis ao mesmo tempo e os coloca em um ambiente de pressão similar ao da vida real. Curiosamente, essas simulações também costumam divertir os alunos.

Para Vicente (2001), os jogos de empresas não são um modismo e sim uma tendência que vem ganhando força. Para o autor, esta categoria de jogos associa o prazer lúdico à capacidade de raciocínio analítico e a habilidade na tomada de decisão. Segundo o mesmo, pessoas que participam desse tipo de jogo possuem menos dificuldade em fazer análises racionais e em tomar decisões, habilidades que estão muito relacionadas ao dia-a-dia das organizações.

Pelas situações que têm que superar e pela pressão dos concorrentes pela liderança, os participantes de um jogo de empresas costumam ter um grande envolvimento emocional durante a aplicação do mesmo. Este estado de tensão, que faz parte da ideia do jogo, acaba fazendo com que os conceitos aprendidos durante o jogo sejam mais bem assimilados pelos participantes. Mesmo as equipes que cometem erros ganham experiência, pois esses erros serão evitados futuramente em suas vidas profissionais. 0 aprendizado se torna extremamente rico para os participantes uma vez que eles podem verificar as conseqüências de suas decisões uma após a outra. (SAUAIA, 1995; MIYASHITA, 1997; VICENTE, 2001)

Segundo Peixoto, Veloso e Lopes (2003), durante o jogo as pessoas revelam facetas de seu caráter que normalmente não exibem por recear sanções. Para os autores, devido ao ambiente permissivo, as vivências são espontâneas e surgem comportamentos assertivos ou nãoassertivos, trabalhados por meio de análise posterior ao jogo. As conclusões servem de base para reformulações ou reforço de atitudes e comportamentos. O objetivo não é então identificar as falhas e os acertos pessoais como forma de se criticar e se promover retaliações, mas sim a maneira de identificar os pontos que devem melhor ser trabalhados tanto em habilidades técnicas quanto comportamentais. Os autores afirmam que no decorrer do jogo é possível avaliar o grau de percepção dos participantes, a sua multidisciplinaridade, a sua capacidade de organização tanto técnica quanto em grupo, a habilidade de planejamento e cumprimento do mesmo, a habilidade de tomar decisões acertadas em pequenos espaços de tempo, muitas vezes, sem se ter as informações necessárias disponíveis e a capacidade de priorizar as atividades e agir proativamente.

Para Gramigna (1993), o jogo de empresas possui algumas características que se fundamentam em sua concepção:

- Possibilidade de modelar a realidade da empresa: de fato o jogo deve reproduzir o ambiente de uma empresa, desde situações até as reuniões dos participantes para execução de uma decisão;

- Papéis claros: consistem em três tipos (estruturados, semi-estruturados e desestruturados). Nos estruturados os participantes têm a responsabilidade de se caracterizar de acordo com o perfil recebido. No caso do papel semi-estruturado, o 
facilitador indica de maneira genérica como cada um deve exercer seu papel. E por fim, papéis desestruturados, em que o grupo pode escolher a forma que preferir de acordo com o problema exposto pelo facilitador. Este último deve ser de forma espontânea;

- Regras claras: o facilitador de alguma forma deve expor as regras do jogo de empresas. Tais regras que são válidas para os benefícios e para as punições. Vale lembrar que o facilitador pode utilizar recursos extras como data-show, transparências, flip-chart, lousa, entre outros.

\section{Aplicações de jogos}

Nagamatsu et al. (2006) fizeram uma pesquisa com 153 alunos de cursos de graduação em administração e de pós-graduação (nível lato sensu). No decorrer de seu trabalho, os autores procuraram evidenciar a importância da utilização dos jogos de empresas no processo de ensino-aprendizagem. Em suas conclusões, eles argumentam que a aplicação da técnica do jogo de empresas pode ser utilizada para o desenvolvimento dos futuros profissionais que ingressarão no ambiente empresarial, auxiliando na formação de executivos e gerentes de empresas, contribuindo para seu processo de aperfeiçoamento e treinamento gerencial e facilitando o processo de inserção competitiva desses estudantes no mercado de trabalho atual. Como resultados de sua pesquisa, demonstraram que os itens relacionados ao desenvolvimento de competências, habilidades e atitudes estão constantemente presentes durante o processo de treinamento. Um outro aspecto destacado pelos autores refere-se à possibilidade do aprimoramento de um pensamento estratégico por parte dos participantes em que eles conseguem ter uma visão do todo organizacional, com a devida interpretação de cenários e situações.

Althoff, Colzani e Seibel (2009) aplicaram um jogo de empresas em uma turma do curso de graduação em engenharia de produção, referenciada à disciplina de sistemas produtivos. Os autores concluíram que a utilização de técnicas de ensino baseadas em jogos de empresas no ensino da engenharia de produção apresenta bons resultados quanto ao desenvolvimento intelectual dos participantes, pois proporciona um melhor entendimento da teoria utilizando o recurso da simulação como aplicação prática do conteúdo. Para eles as dinâmicas trazem para dentro da sala de aula a sensação de aprender em um ambiente real, facilitando a assimilação dos conceitos a serem aplicados na vida profissional dos acadêmicos. Para os autores, quando se faz o uso de técnicas de ensino baseadas em jogos e simulações, é essencial promover uma discussão entre os participantes quanto aos resultados obtidos. É a partir destas discussões que surge a oportunidade de agregar conhecimento aos alunos, instigando a análise da situação real, promovendo o crescimento do senso intuitivo que somente a experiência proporciona e comparando a teoria acadêmica aos resultados alcançados com a prática.

Bergamaschi Filho e Albuquerque (2009) aplicaram um jogo de empresas em uma turma de graduação em contabilidade. Segundo os autores a utilização de jogos empresariais revela-se de grande valia na preparação dos futuros tomadores de decisão ao permitir que situações do cotidiano empresarial sejam experimentadas de forma simulada, possibilitando também a aplicação e integração dos conhecimentos teóricos. Para eles da mesma forma, a aplicação de tais jogos, permite ao professor uma forma eficiente de demonstrar a teoria transmitida. Os autores argumentam que na verdade, busca-se formas de se aprimorar as técnicas de ensino em função das novas possibilidades trazidas pela evolução das ferramentas e recursos 
tecnológicos.

Freitas e Santos (2003) possuíam dois grandes objetivos em sua pesquisa: conhecer a percepção dos alunos de graduação dos cursos de administração e ciências contábeis sobre a utilização dos jogos de empresas enquanto metodologia de ensino; e avaliar se o desempenho apresentado na gestão das empresas simuladas por estudantes de administração era significativamente diferente daquele alcançado por estudantes de ciências contábeis em função da adequação entre a formação acadêmica e as práticas inerentes ao jogo. Para tanto os autores aplicaram um jogo de empresas em três turmas do curso de graduação em administração e em três turmas do curso de graduação em ciências contábeis, nas quais ao final dos trabalhos aplicou-se um questionário que visava coletar as impressões dos estudantes a respeito desta metodologia, após terem conhecido seu funcionamento. Além disso, os resultados alcançados pelas empresas, medidos através do cálculo dos seus índices econômico-financeiros, serviram de parâmetro para a avaliação e comparação do desempenho da gestão promovida pelos dois grupos de estudantes. Os resultados obtidos pelos autores evidenciaram que os estudantes acreditam que a participação em um jogo de empresas além de motivá-los, possibilita que seja promovida a integração entre as diversas disciplinas que compõem a formação de administradores e contadores, aperfeiçoando suas habilidades através do exercício das práticas gerenciais. Para os autores as respostas dos questionários demonstraram ainda que a maioria dos alunos, nos dois grupos de estudantes, avaliou sua participação no JE como ativa; que aprenderam bastante com a experiência didática vivenciada; elegeram a possibilidade de aprimorar suas habilidades de trabalho em equipe como a principal vantagem do jogo de empresas; e consideraram a técnica como uma eficiente metodologia de ensino, por facilitar o aprendizado. Quanto a segunda hipótese de seu estudo, os autores, constataram que apesar de se posicionarem, em suas decisões, de forma diferente frente ao jogo de empresas, não houve diversidade nos resultados alcançados pelas empresas geridas por estudantes de administração ou de ciências contábeis. Portanto, segundo os autores, estatisticamente, os grupos apresentaram desempenhosiguais.

\section{Jogo versus outros métodos pedagógicos}

Para Miyashita (1997), os jogos de empresas constituem um instrumento muito importante, pois completam outros métodos tradicionais de ensino, como as aulas expositivas, as leituras e o método do caso. 0 autor argumenta que se comparado ao aprendizado através de aulas/leituras os jogos de empresas, para o mesmo tempo de dedicação, conseguem uma abrangência de conteúdo muito menor, porem, a fixação desse conhecimento pelo método do jogo é muito maior devido ao envolvimento emocional do jogador gerado pelas situações que tem que superar durante a partida. Segundo Miyashita (1997), tanto nas leituras quanto nas aulas, o aluno obtém menor fixação do conhecimento porque só poderá consolidar seu aprendizado no momento em que puder verificar na prática a validade dos conceitos lidos e ouvidos, o que só costuma acontecer posteriormente na vida profissional, quando o indivíduo tem oportunidade de utilizar estes conceitos na solução de problemas concretos do dia-a-dia das empresas.

Para Oliveira e Sauaia (2009), os métodos tradicionais de ensino costumam colocar os alunos em posição passiva e tornam as aulas expositivas pouco envolventes. Segundo os autores, o grande desafio da educação atualmente concentra-se em propiciar um aprendizado significativo aos educandos, mas para eles, o modelo tradicional de ensino onde a figura do educador é o foco das ações parece não ser suficiente para permitir que exista um aprendizado pleno. Os autores argumentam que a aprendizagem vivencial, representada em 
seu estudo pelos jogos de empresas ou simulações empresariais, representam um esforço considerável para compreender a integração entre a teoria e a prática gerencial. Para os autores, dentre os benefícios sugeridos aos jogos de empresas, os que mais se destacam em criar condições para o desenvolvimento de competências gerenciais são: a integração dos conhecimentos garantindo uma visão sistêmica da organização, a possibilidade de reduzir a lacuna entre a teoria e prática e o desenvolvimento de habilidades e comportamentos em questões que requerem liderança e trabalho em equipe.

Para Arbex et al.(2006), o formato tradicional de ensino, no qual o professor é o agente ativo e o aluno é mero ouvinte, há tempos, tem mostrado sinais de estagnação. Segundo os autores formas alternativas de transmissão do conhecimento passam a ser demandadas pela sociedade, inclusive pelos próprios alunos. Nesse contexto os autores argumentam que os jogos de empresas mostram seu valor à medida que se encaixam na chamada aprendizagem vivencial, compreendida como um método de aprendizagem onde o professor atua mais como um facilitador e o aluno é o centro da ação, aprendendo com sua própria experiência. Para eles um dos principais pontos positivos da utilização de jogos de empresas consiste no estímulo ao raciocínio analítico e ao planejamento e elaboração de estratégias de empresas.

Li e Baillie (1993) e Wolfe e Luethge (2003) ressaltam que o forte envolvimento do aluno, permitido pelo método experimental, é uma das vantagens da utilização dos jogos para o processo de ensino e aprendizagem. Randel et al. (1992) afirmam que um elevado nível de aprendizagem correlaciona-se a um elevado nível de participação do aprendiz nojogo.

Em comparação com leituras e aulas, que costumam ser mais cansativas, até porque levam a um menor envolvimento do aluno, os jogos pelo seu caráter lúdico associado à necessidade de raciocínio lógico e da habilidade de tomada de decisão, tornam mais agradável e, assim, menos custoso o aprendizado. (SAUAIA, 1995; MIYASHITA, 1997; VICENTE, 2001)

Segundo Knabben e Ferrari (1997), a grande vantagem da simulação como metodologia de ensino/aprendizagem, é o fato de conseguir proporcionar ao aluno, dentro do espaço das salas de aula, uma aproximação muito consistente entre a teoria e a prática, simulando uma situação empresarial, com os departamentos de uma empresa, os estudos de mercado, a divisão de trabalho, as reuniões, decisões financeiras e outras.

Miyashita (1997) faz um paralelo entre os jogos de empresas e o método do caso. Para o autor, assim com os jogos o método do caso força uma participação ativa do aluno e aumenta a habilidade de diagnóstico de problemas práticos. Segundo o autor, no entanto, existe uma grande desvantagem do método do caso em relação aos jogos: nos casos estudados geralmente existe um campo limitado de busca de soluções, uma vez que as questões estão geralmente delimitadas no início da discussão. Além disso, para Miyashita (1997), o horizonte de decisão é menor que nos jogos, onde a dinâmica das rodadas sucessivas, faz com que as decisões tenham sempre um caráter de novidade, pois dificilmente uma empresa se encontra no mesmo estado em momentos distintos da partida.

Goldschmidt (1977) afirma que o jogo de empresas se aproxima de um estudo de caso, onde adicionamos duas variáveis: uma é o feedback - o retorno das informações; a outra é a dimensão temporal que, geralmente, os casos não têm. Para Motta, Paixão e Melo (2009), essa diferença ilustra as principais vantagens de utilização dos jogos de empresas no processo de ensino-aprendizagem em gestão: a capacidade de observar as conseqüências de suas decisões e a possibilidade de se aprender com os erros. Li e Baillie (1993) ainda apontam o grande 
estímulo à participação dos alunos como outra vantagem da aplicação de jogos de empresas.

Para Stahl e Lopes (2004), a vantagem dessas técnicas é que proporcionam um maior realismo e integração na medida em que cada estudante assume papéis a serem desenvolvidos, onde deverão tomar decisões e apresentar determinados comportamentos, habilidades e atitudes, além de envolver uma série de sentimentos como cooperação, competição, insegurança, etc. Para os autores, esse tipo de atividade pode também conduzir os alunos a uma série de reflexões sobre o seu processo de ensino-aprendizado, verificando como determinadas teorias são aplicadas e quais os resultados que uma estratégia pode gerar, bem como a importância de estar sempre monitorando o ambiente a fim de adaptar as estratégias de curto prazo na busca dos objetivos organizacionais. Os autores afirmam ainda que a vantagem da utilização de jogos interativos no processo de ensino-aprendizado se deve justamente à flexibilidade, uma vez que o feedback de informações é aleatório e imprevisível para os participantes, exigindo uma constante reavaliação das estratégias, o que proporciona um grau ainda maior de motivação e aprendizado, principalmente porque esta atividade proporciona o processo contínuo de administração (planejamento, avaliação e controle).

Para Rodrigues e Riscarrolli (2001), um dos grandes problemas dos jogos de empresas com relação a seu valor pedagógico é a explicitação de tudo que o jogo pretende desenvolver com o exercício. Segundo os autores, a explicitação das aptidões administrativas a serem desenvolvidas nos jogos dá maior objetividade às avaliações dos instrutores e maior consciência aos jogadores (alunos), relativamente aos seus desempenhos. Para os autores, não importa apenas que eles vençam, ou cheguem a determinado cenário com as empresas. É necessário também que os jogadores entendam o que está sendo desenvolvido neles como administradores ou tomadores de decisões.

Para Miyashita (1997), uma clara limitação nos jogos de empresas é a quantidade de conceitos que podem ser explorados em uma partida que são bem mais limitados do que os que podem ser adquiridos em um bom texto cientifico. Porem, para o autor, uma deficiência dos livros é que neles se pede uma solução de uma determinada situação de decisão, sem preocupação com o que ocorreria no futuro, tanto a médio quanto a longo prazo, diferente do que ocorre no jogo de empresa onde existe uma seqüência de decisões, onde os resultados de uma rodada influenciam na tomada de decisão da rodada seguinte, procurando simular o que realmente ocorre na vida real. Outra questão levantada pelo autor é que os professores, expositores e autores de textos de leitura expõem somente relatos de experiências de terceiros que são muito menos marcantes do que a experiência pessoal, que é encontrado nos métodos vivencias como o jogo de empresas. Resumindo seu pensamento, Miyashita (1997) diz que o aprendizado via leitura ganha em amplitude de conhecimento enquanto que os jogos de empresas ganham em profundidade.

Para Motta, Melo e Paixão (2009), há uma fragilidade em estudos que tentam comprovar a validade dos jogos enquanto prática educacional capaz de contribuir para a formação de estudantes. Os autores observam que há um pressuposto de que todos os participantes em jogos de empresas têm o mesmo nível de envolvimento nas atividades do jogo. Para os autores, ao se assumir tal posição, nega-se a variedade de habilidades e interesses entre os diversos aprendizes, o que implica diretamente no desempenho, tanto individual quanto grupal. Desta forma, os autores afirmam que não se deve igualar aprendizagem ao desempenho no jogo. Para eles o papel do envolvimento dos alunos para a efetividade da aprendizagem com jogos de empresas é de elevada importância e destaca os princípios construtivistas do jogo e sua adequação enquanto técnica de aprendizagem vivencial. Segundo 
os mesmos, os muitos anos de ênfase no tradicionalismo das aulas expositivas como forma exclusiva de desenvolvimento do ensino retirou do aprendiz a responsabilidade pelo seu aprendizado. Para os autores, muitos são os métodos e técnicas (método do caso, aprendizagem baseada em problemas, portfólio, estágio supervisionado, pesquisa de campo, visita técnica, jogos de empresas, dentre outros) utilizados em sala de aula ou fora dela para devolver esta responsabilidade ao aprendiz, entretanto nem todas são capazes de efetivar tal pretensão.

Peixoto, Veloso e Lopes (2003) indicam como fatores limitantes do método dos jogos de empresas que os trabalhos envolvendo essa ferramenta devem ter um tempo adequado para sua realização; há necessidade por parte dos docentes, de um profundo conhecimento do jogo, e de suas etapas; por se tratar de um método construtivista do conhecimento, tem-se a necessidade dos alunos estarem altamente motivados e interessados, uma vez que o trabalho deve ser inteiramente realizado por eles.

\section{Metodologia}

0 presente estudo caracteriza-se, do ponto de vista de sua finalidade, como metodológico, já que cria um jogo que tenta simular a realidade; e descritivo, uma vez que busca mostrar a correlação entre a assimilação de conhecimentos e a participação em um jogo de empresas. No que diz respeito aos meios, pode ser entendido como sendo de laboratório, pois está baseado em um jogo que busca simular em computador o dia-a-dia de uma empresa; e também como experimental uma vez que o grupo pesquisado foi dividido em dois para testar a influência da participação no jogo em relação à assimilação dos conceitos estudados.

\section{Construção, conceitos e variáveis do jogo}

As ideias utilizadas na construção do aplicativo surgiram da necessidade de se criar um jogo de empresa interdisciplinar que vise dar algum tipo de experiência vivencial a estudantes no final de seus cursos superiores, para que os mesmos não cheguem ao mercado de trabalho apenas com a visão de sua área de formação e sem nenhuma noção de quais resultados suas decisões podem gerar no dia-a-dia das empresas.

Na busca da resposta de como deve ser e quais conceitos deve trabalhar um jogo com essas características, foram pesquisados alguns trabalhos acadêmicos, onde se pode perceber que, em boa parte das vezes, o jogo criado tem uma finalidade específica.

Bouzada (2001) e Miyashita (1997), por exemplo, criaram jogos cujo foco era Logística. Outros exemplos de jogos específicos para esta área podem ser encontrados em Bouzada (2011). Fernandes (2002) se ateve à parte orçamentária e Hein e Rabenschlag (2007) à parte de custos. Já Freitas e Lopes (2008) criaram um jogo com temática no mercado de capitais.

Algumas ideias e conceitos para o jogo trabalhado nesta pesquisa foram retirados desses trabalhos e outros foram concebidos pelos próprios autores.

O jogo foi criado para funcionar com um mínimo de duas empresas e um máximo de dez. Estas empresas disputam o mercado brasileiro vendendo polpa de frutas congelada. 0 mercado de polpa de frutas congelada é bastante diversificado, compreendendo bares, restaurantes, lanchonetes, indústrias de laticínio, indústrias de sucos, indústrias de doces, indústrias de sorvetes e supermercados. Cada empresa é administrada por uma equipe que, exercendo o papel da diretoria, tomará decisões nas mais diversas áreas como, por exemplo, produção, 
marketing, custos e logística.

Uma aplicação do jogo é composta de 5 rodadas, onde a primeira corresponde às decisões pré-operacionais e as outras correspondem aos quatro trimestres de umano.

O objetivo de cada equipe é administrar da melhor maneira a sua empresa, de modo a conseguir o maior lucro possível. A equipe vencedora será aquela que, ao final do jogo, tiver acumulado o resultado financeiro mais positivo.

Em um primeiro momento, as equipes decidem sobre a macro-estrutura da empresa, isto é, localização da fábrica, tamanho do armazém (quando houver), tipo e quantidade de maquinário para o processo produtivo e o tipo de mão-de-obra que será utilizada. Esta etapa é muito importante, porque nenhuma fábrica ou armazém poderá ser aberto ou ter sua localização alterada após as decisões iniciais. 0 tipo de máquina e a qualificação da mão-deobra também não podem ser alterados. Por isso, as equipes devem dedicar atenção especial a este momento, pois ele poderá influenciar fortemente o desempenho das empresas. Após o set-up inicial e no decorrer do jogo, cada equipe deverá tomar decisões trimestrais (do ponto de vista da cronologia da empresa) operacionais (determinação dos preços, aquisição de matéria-prima, programação da produção e transportes), após receber o resultado da interação das suas decisões com as das outras equipes no trimestre anterior.

Na fase de set-up, cada equipe, com uma planilha contendo informações do mercado e um capital inicial de R\$ 7.000.000,00 (sete milhões de reais), deve decidir: localização da fábrica; tipo de máquina; quantidade de máquinas ; qualificação dos operários; e capacidade do armazém.

Depois de todas as decisões tomadas, a equipe saberá o custo total de implantação, que é composto do custo da fábrica mais o custo das máquinas mais o custo do armazém.

A equipe também saberá o valor do saldo financeiro, que é o resultado da diminuição do custo total de implantação do capital inicial. Caso o custo total de implantação supere o valor do capital inicial, será diminuída proporcionalmente a quantidade de máquinas e a capacidade do armazém para que o valor se encaixe dentro do limite do capital inicial.

Outra informação na planilha de decisão inicial é o valor do custo fixo trimestral, que guarda relação com o tamanho da fábrica e do armazém. Além desse valor, será somado o valor da depreciação das máquinas, que é de $10 \%$ ao ano, e da depreciação da fábrica e do armazém, que é de $5 \%$ ao ano.

Após as decisões iniciais serem tomadas, os terrenos são adquiridos, as fábricas e armazéns construídos e as máquinas instaladas. A partir deste momento, o jogo entra em um regime mais dinâmico.

O início da planilha de decisões trimestrais traz informações sobre o desempenho no trimestre anterior: estoque final; devoluções; estoque inicial; saldo em caixa no trimestre anterior; receitas por região; custos extras; despesas financeiras e saldo em caixa atual; custo fixo trimestral.

Na segunda parte da planilha começam os inputs: quantidade de funcionários; produção; quantidade de MP por quilo de produto; fornecedor; investimento em qualidade; investimento em propaganda; e prioridades geográficas para as vendas. As equipes também devem registrar suas decisões para cada região do país: preço de venda; investimento em 
vendas; e transportador.

As rodadas seguintes continuam com decisões operacionais, onde as equipes basicamente definem sua produção, preço de venda e investimentos em qualidade e propaganda. A definição de quanto de produto é demandado em cada região para cada equipe se dá em função do preço definido, da qualidade do produto, do investimento em propaganda e em vendas e do histórico das entregas anteriores. A quantidade efetivamente vendida em cada região depende da demanda e do montante oferecido para cada região, definido em função das prioridades geográficas. Após cada rodada, as equipes recebem o arquivo com as informações do que efetivamente aconteceu com as vendas de seus produtos em cada um das regiões.

Após processada a quinta rodada, é definida a equipe vencedora, quando é disponibilizada a planilha de resultados, onde os jogadores podem encontrar todas as informações necessárias para uma análise de seu desempenho no jogo. Algumas informações contidas na planilha são: capacidade de produção; ociosidade (\%); demanda; atendimento da demanda (\%); custos; e saldo final de caixa.

De posse da planilha de resultados, as equipes preparam suas apresentações finais onde devem expor suas decisões tomadas ao longo do jogo e as ferramentas de apoio desenvolvidas, destacando erros e acertos, e fazer uma comparação com as outras equipes.

Ao final das apresentações, o aplicador do jogo realiza o fechamento da atividade, quando procura mostrar para as equipes como as decisões de cada empresa impactaram os seus indicadores de desempenho, incluindo o resultado final

\section{Coleta e tratamento de dados}

Foi solicitado aos alunos da turma escolhida que se dividissem em dois grupos, onde um grupo participaria do jogo e o outro seria o grupo de controle.

Para o grupo que participaria do jogo, foi apresentado o manual do mesmo e solicitado que se dividissem em 4 equipes. As equipes participaram do jogo e ao final da quinta rodada fizeram uma apresentação sobre seu desempenho.

Ao final das apresentações, o aplicador atribuiu uma nota individual para cada aluno, tentando refletir o seu nível de participação na atividade, a coerência das suas decisões e a intensidade do seu empenho. Também foi atribuída uma nota coletiva para cada equipe, refletindo simplesmente o desempenho financeiro da empresa administrada por ela. É claro que na simulação, assim como na vida real, pode acontecer de a decisão ser ruim, mas o resultado ser bom ou vice-versa, por conta do acaso. A nota de participação tentou considerar a qualidade e coerência das decisões, na expectativa de mitigar estes eventuais efeitos do acaso.

Finalmente, cada um dos 16 alunos pode ter sua nota final na atividade obtida pelo cálculo da média ponderada entre a sua nota individual na apresentação (70\%) e a nota coletiva da sua equipe (30\%).

Após as apresentações das equipes, foi aplicada uma prova para todos os alunos (grupo que participou do jogo e grupo de controle). A prova foi construída baseada em questões do ENADE (2009) que envolveram algum aspecto de interdisciplinaridade. 
Depois da aplicação-teste do jogo e da apresentação final das equipes, houve condições de contrapor a problemática da pesquisa, respondendo como deve ser e quais conceitos deve-se trabalhar em um jogo de empresa interdisciplinar que vise dar algum tipo de experiência vivencial a estudantes no final de seus cursos superiores, para que os mesmos não cheguem ao mercado de trabalho apenas com a visão de sua área de formação e sem nenhuma noção de quais resultados suas decisões podem gerar no dia-a-dia das empresas.

Quanto às hipóteses levantadas e apresentadas na Introdução (H1 e H2), de posse das notas, pensou-se em fazer um teste $t$ de duas amostras (grupo do jogo e grupo de controle) em relação à nota da prova para medir se a assimilação dos conceitos para os participantes do jogo foi superior à dos que não participaram (H1).

Mas como as duas amostras são pequenas (16 elementos cada), a realização de tal procedimento estatístico só é possível se as duas populações (de onde foram retiradas as amostras) seguirem a distribuição Normal. Então, um teste qui-quadrado de aderência foi conduzido, rejeitando a hipótese nula de normalidade a 0,05 de significância para o primeiro grupo (valor $\mathrm{p}=0,0376$ ) e para o segundo grupo (valor $\mathrm{p}=0,0426$ ).

Em vista disso, ao invés de ter sido realizado o teste $t$ de duas amostras, foi conduzido o seu equivalente não-paramétrico, o teste de Mann-Whitney, que não exige a normalidade das populações.

Para analisar se os participantes com melhores resultados no jogo também foram os que tiveram melhor assimilação dos conceitos (H2), foram feitas duas análises de correlação (apenas para o grupo do jogo) para testar (i) a relação entre o desempenho financeiro da equipe de cada aluno e a sua nota na prova; e (ii) a relação entre a nota individual de cada aluno no jogo e a sua nota na prova.

\section{Limitações}

Essa pesquisa fica limitada por algumas razões:

- Generalização - Por ter sido feita com uma pequena amostra, não podemos afirmar que os resultados serão os mesmos em outros grupos;

- Viés de não-resposta - Como os próprios alunos optaram em participar do jogo ou fazer parte do grupo de controle, pode ter ocorrido uma situação onde os melhores alunos decidiram jogar e os piores escolheram o grupo de controle, enviesando os resultados;

- Desempenho coletivo - Por também ser avaliado pela participação de sua equipe no jogo, algum aluno pode se beneficiar do desempenho de sua equipe, sem ter tido um bom desempenho individual;

- Subjetividade na avaliação individual - Como foi atribuída uma nota pela apresentação final dos grupos, fica claro que o pesquisador pode se influenciar por algum aspecto no momento de fazer essa avaliação;

- Qualidade da prova enquanto instrumento mensurador da capacidade do aluno As questões escolhidas podem não estar à altura de avaliar a capacidade dos alunos. 


\section{Apresentação e análise dos resultados}

Após terminadas as 5 rodadas do jogo, as equipes tiveram dois encontros de uma hora e meia para prepararem suas apresentações finais. As apresentações deveriam mostrar onde cada equipe acertou e onde errou. Todos os membros da equipe deveriam participar da apresentação para receber nota.

Depois de terminadas as apresentações, todos os alunos da turma (participantes do jogo e grupo de controle) fizeram a prova final. A tabela 1 a seguir relaciona as notas dos alunos no jogo (somente para os 16 participantes) e na prova (para os participantes do jogo e para o grupo de controle), além do desempenho financeiro da equipe de cada participante no jogo.

Conforme colocado na Introdução, a hipótese 1 (H1) pretendia verificar se a assimilação dos conceitos para os participantes do jogo seria superior à dos que não participaram do jogo. Após realizado um teste (não-paramétrico) de Mann-Whitney para comparação de duas medianas (grupo do jogo e grupo de controle) em relação à nota da prova, o valor $p$ encontrado foi de 0,0001 .

Tabela 1 - Notas no jogo e na prova e desempenho financeiro da equipe no jogo

\begin{tabular}{|c|c|c|c|}
\hline Nome & Nota da prova & Resultado Financeiro no Jogo & Nota no Jogo \\
\hline Aluno 1 & 9,40 & 7.789 .343 & 9,30 \\
\hline Aluno 2 & 8,10 & 7.789 .343 & 9,30 \\
\hline Aluno 3 & 9,40 & 7.789 .343 & 10,00 \\
\hline Aluno 4 & 9,40 & 7.789 .343 & 9,30 \\
\hline Aluno 5 & 9,40 & 13.564 .667 & 10,00 \\
\hline Aluno 6 & 6,90 & 13.564 .667 & 10,00 \\
\hline Aluno 7 & 6,90 & 13.564 .667 & 9,30 \\
\hline Aluno 8 & 10,00 & 13.564 .667 & 9,30 \\
\hline Aluno 9 & 6,90 & -8.329 .234 & 10,00 \\
\hline Aluno 10 & 8,10 & -8.329 .234 & 9,30 \\
\hline Aluno 11 & 8,10 & -8.329 .234 & 10,00 \\
\hline Aluno 12 & 8,80 & -8.329 .234 & 10,00 \\
\hline Aluno 13 & 3,10 & 9.639 .844 & 10,00 \\
\hline Aluno 14 & 8,80 & 9.639 .844 & 7,90 \\
\hline Aluno 15 & 8,10 & 9.639 .844 & 9,30 \\
\hline Aluno 16 & 6,90 & 9.639 .844 & 8,60 \\
\hline Aluno 17 & 4,40 & & \\
\hline Aluno 18 & 3,80 & & \\
\hline Aluno 19 & 3,10 & & \\
\hline Aluno 20 & 3,80 & & \\
\hline Aluno 21 & 5,00 & & \\
\hline Aluno 22 & 3,10 & & \\
\hline Aluno 23 & 3,10 & & \\
\hline Aluno 24 & 7,50 & & \\
\hline Aluno 25 & 4,40 & & \\
\hline Aluno 26 & 4,40 & & \\
\hline Aluno 27 & 3,10 & & \\
\hline Aluno 28 & 3,80 & & \\
\hline Aluno 29 & 3,10 & & \\
\hline Aluno 30 & 3,80 & & \\
\hline Aluno 31 & 4,40 & & \\
\hline Aluno 32 & 4,40 & & \\
\hline
\end{tabular}


Com o resultado do valor $p$ do teste sendo praticamente igual a zero, podemos dizer que não existe igualdade entre a mediana das populações (prevalecendo a hipótese alternativa unicaudal: nota do grupo do jogo maior que a nota do grupo de controle). Desta forma, a hipótese 1 (H1) é confirmada.

O teste de comparação de duas medianas utilizado presume que as duas variâncias populacionais sejam equivalentes. Para verificar a validade de tal premissa, foi realizado um teste $F$ de igualdade de duas variâncias. 0 valor $p$ resultante foi 0,1155 , não fornecendo evidência amostral suficiente para rejeitar a hipótese nula de igualdade das variâncias. Assim sendo, a premissa utilizada no teste parece válida.

Já a hipótese 2 (H2) pretendia verificar se os participantes com melhores resultados no jogo também seriam os que teriam a melhor assimilação dos conceitos. Para tanto, foram feitas duas análises de correlação (apenas para o grupo do jogo) para testar (i) a relação entre o desempenho financeiro da equipe de cada aluno e a sua nota na prova; e (ii) a relação entre a nota individual de cada aluno no jogo e a sua nota na prova.

0 primeiro teste de correlação teve como resultado um índice de correlação linear de Pearson (r) igual a -0,0011, indicando não haver correlação linear entre o desempenho financeiro da equipe de cada aluno e a sua nota na prova.

0 segundo teste de correlação teve como resultado $r=-0,1849$, revelando uma correlação linear muito baixa entre a nota individual de cada aluno no jogo e a sua nota na prova. Os baixos índices de correlação encontrados em ambos os testes (mesmo com amostras pequenas, para as quais geralmente é mais fácil encontrar índices mais altos) apontam para a rejeição de $\mathrm{H} 2$.

Aparentemente, depois de realizados os testes para as duas hipóteses, o que se pode dizer é que o importante é a participação do aluno no jogo. Essa participação (confirmação de H1), e não necessariamente o resultado (rejeição de H2), é que faz com que o aluno tenha uma maior assimilação dos conceitos propostos.

\section{Considerações finais}

A busca por métodos de ensino que tragam melhores resultados para o aprendizado dos alunos tem sido alvo de muitas pesquisas. Um dos métodos que vem se destacando é o dos Jogos de Empresas, que muitos pesquisadores (RODRIGUES; RISCARROLI, 2001; SILVA; SAUAIA, 2008), afirmam ser na atualidade um dos instrumentos pedagógicos mais eficientes para a finalidade de preparar futuros gestores.

Além disso, tal modalidade parece mais adequada para ajudar os educadores em alguns dos seus principais desafios atuais, como, por exemplo, as salas de aula lotadas. A dinâmica dos jogos empresariais permite que os mesmos sejam aplicados de forma remota e, mesmo quando aplicados presencialmente, quebram aquele paradigma de um expositor discursando para uma plateia (bastante inadequado para turmas lotadas), já que a turma se divide em grupos que discutem internamente quais decisões a empresa deve tomar.

Com as instituições de ensino acreditando nisso e cada vez mais incluindo Jogos de Empresas em suas grades curriculares, fica evidente a necessidade de mais pesquisas sobre o tema. Parte do que se encontra na literatura diz respeito a jogos focados apenas em alguma área especifica, como logística, custos ou marketing. 
Em vista da inclusão da disciplina Jogos e Simulações de Negócios na grade curricular dos cursos de Administração, Contabilidade e Economia da Faculdade Moraes Junior Mackenzie Rio (com o intuito de testar em um ambiente simulado alguns dos conhecimentos que se fazem necessários para que seus alunos atuem de forma competente no mercado de trabalho) e da falta de um jogo que atendesse a todos os requisitos interdisciplinares que se espera trabalhar, esta pesquisa buscou responder como deve ser e quais conceitos deve-se trabalhar em um jogo de empresa interdisciplinar que vise dar algum tipo de experiência vivencial a estudantes no final de seus cursos superiores, para que os mesmos não cheguem ao mercado de trabalho apenas com a visão de sua área de formação e sem nenhuma noção de quais resultados suas decisões podem gerar no dia-a-dia das empresas.

Dentre os objetivos intermediários deste trabalho, o primeiro era definir os conceitos, as decisões e suas alternativas e as características organizacionais que seriam trabalhadas no jogo. Como a ideia era fazer um jogo interdisciplinar, foi definido que o jogo trabalharia conceitos de Contabilidade Gerencial (pois as equipes deveriam decidir sobre o planejamento financeiro e a estrutura patrimonial), Finanças (pois as equipes deveriam planejar seu orçamento), Custos Industriais (pois as equipes deveriam calcular seus custos de produção), Marketing (pois as equipes deveriam definir suas estratégias de preço, calcular previsões de demanda e definir investimentos em propaganda), Produção (pois as equipes deveriam decidir os sistemas de produção, admissão ou demissão de pessoal, políticas de compra e estocagem da matéria-prima e escolher o ritmo de operação da empresa), Princípios de Administração e Engenharia Econômica (pois as equipes deveriam decidir o investimento em imobilizado/tipos de equipamentos) e Logística (pois as equipes deveriam decidir o local para instalação da fábrica e o tipo de transportadora que utilizariam para entregar seus produtos).

O segundo objetivo era desenvolver o modelo matemático do jogo, utilizando planilhas Excel. Para cumpri-lo, foram criados dois arquivos em Excel, o arquivo "Arbitro.xls" e o arquivos "EquipeX.xls". 0 arquivo "EquipeX.xls" seria o arquivo entregue para as equipes participantes do jogo para que elas preenchessem com suas decisões. Já o arquivo "Arbitro.xls" continha as formulas e as funções necessárias para calcular o resultado da interação das decisões das equipes participantes do jogo.

0 terceiro objetivo era realizar a aplicação-teste do jogo, refinando os modelos através dos feedbacks obtidos. Para cumprir com esse objetivo, o jogo foi aplicado em uma turma do ultimo período do curso de Administração da Faculdade Moraes Junior, conforme descrito na metodologia.

O quarto objetivo era avaliar a assimilação dos conceitos para os participantes do jogo em comparação à dos não participantes. Esta assimilação seria testada pela hipótese 1 (H1), apresentada na Introdução. Com os resultados, que podem ser verificados na Apresentação e análise dos resultados, podemos confirmar o que dizem Sauaia (1995), Miyashita (1997) e Vicente (2001), que afirmam que os conceitos teóricos são mais bem assimilados pelos participantes de jogos.

0 quinto e último objetivo intermediário deste trabalho era medir a relação entre o desempenho das equipes no jogo e a assimilação dos conceitos dos seus integrantes. Este objetivo seria testado pela hipótese 2 (H2), apresentada na Introdução. Com os resultados, que podem ser verificados na Apresentação e análise dos resultados, a hipótese 2 (H2) é rejeitada. Esse resultado vem, em parte, ao encontro do que dizem Rodrigues e Riscarrolli (2001). Para os autores, não importa apenas que os participantes vençam, ou cheguem a determinado cenário com as empresas; é necessário também que os jogadores entendam o 
que está sendo desenvolvido neles como administradores ou tomadores de decisões.

Juntando o resultado dos dois testes (H1 e H2), o que se pode concluir é que o importante para o aprendizado é a participação no jogo e não o resultado em si. Essa participação, e não o resultado, é que faz com que o aluno tenha uma maior assimilação dos conceitos propostos. É importante ressaltar que isso não deve ser claramente explicitado para o aluno, pois o mesmo pode participar do jogo de uma forma muito relaxada por saber que não haverá nenhum tipo de avaliação, o que pode comprometer o objetivo da aplicação.

Desta forma, pode-se afirmar que o objetivo geral deste trabalho foi cumprido, uma vez que foi criado um jogo de empresas multidisciplinar com todas as suas decisões e alternativas dentro de um contexto organizacional e que esse jogo foi testado em uma turma do ultimo período do curso de Administração da Faculdade Moraes Junior.

Sendo assim, além das contribuições teóricas alcançadas com os testes das hipóteses de pesquisa e com o cruzamento dos seus resultados com a teoria sobre Jogos de Empresas, espera-se ter também contribuído de forma metodológica e prática com o desenvolvimento de um jogo interdisciplinar que acrescente aos estudantes conhecimentos, habilidades e atitudes que os permitam exercer suas atividades de maneira segura dentro das empresas depois de formados - indo ao encontro do que dizem Vasconcellos e Mattar (1998) sobre a necessidade de disciplinas integrativas e atividades práticas para completar os conceitos aprendidos - e contribua para mudar o cenário encontrado por Pereira, Santos e Rech (2008), que concluíram, em sua pesquisa, que os profissionais não estão sendo formados com uma visão global da realidade, que é uma necessidade do mercado globalizado.

0 que se pode perceber durante a aplicação-teste do jogo foi que, como afirmam Freitas e Santos (2003), os estudantes acreditam que a participação em um jogo de empresas, além de motivá-los, possibilita que seja promovida a integração entre as diversas disciplinas que compõem a sua formação, aperfeiçoando suas habilidades através do exercício das práticas gerenciais.

Também foi possível perceber, ao final da atividade, a importância das apresentações finais das equipes e do fechamento por parte doaplicador.

Por se tratar de uma ferramenta de ensino-aprendizado, essas apresentações finais do jogo são de enorme importância, pois nesse momento os jogadores podem trocar experiências, discutindo suas estratégias, seus erros e seus acertos, agregando conhecimento a todos os participantes.

E o fechamento do aplicador oferece a oportunidade de o mesmo mostrar, por exemplo, que: as empresas com maior capacidade instalada tiveram o maior volume de produção ou índice de ociosidade; as empresas que se instalaram nas regiões mais populosas tiveram maiores custos de instalação, mas possivelmente menores custos de transportes; que as empresas que investiram mais em qualidade tiveram maiores custos de produção, mas tenderam a conseguir uma fatia maior do mercado.

Nesse momento, a consolidação do aprendizado acontece de forma mais intensa. Ao longo do jogo, os conceitos vão sendo trabalhados e, de maneira geral, aprendidos. Mas a fixação dos mesmos ocorre com mais força nesse segundo momento, de fechamento da atividade.

Este trabalho não pretende esgotar o tema estudado. Desta forma, com a experiência adquirida, espera-se poder acrescentar algumas sugestões para outros que desejarem 
pesquisar sobre o assunto: aumentar o tamanho da amostra, fazendo a aplicação do jogo (que pode ser disponibilizado para professores interessados) em turmas de Contabilidade, Economia, Engenharia de Produção e Marketing; selecionar os participantes do jogo e os do grupo de controle através de sorteio para evitar que os melhores alunos decidam jogar e os piores façam parte do grupo de controle; juntar um grupo de professores das disciplinas que têm seus conceitos trabalhados no jogo para preparar uma prova específica para avaliação do aprendizado dos participantes no jogo; migrar o modelo do jogo para o ambiente WEB; desenvolver uma aplicação do jogo para utilização em EAD; e expandir o escopo da aplicação, desenvolvendo um modelo de jogo para o setor de serviços (como hospitais ou hotéis), que é muito carente deste tipo de tratamento quantitativo, mais encontrado no setor de manufatura.

\section{Referências}

ALTHOFF, T.; COLZANI, T.; SEIBEL, S. A dinâmica da montadora de canetas - uma simulação baseada em jogos de empresas no ensino da engenharia de produção. In: Encontro Nacional De Engenharia De Produção (ENEGEP), 29., 2009, Salvador. Anais... Salvador: ABEPRO, 2009.

ARBEX, M.; CORRÊA, H.; MELO JUNIOR, A.; RIBAS, C.; LOPES, P. O uso de Jogos de Empresa em Cursos de Graduação em Administração e Seu Valor Pedagógico: um Levantamento no Estado do Paraná. In: Encontro da Associação Nacional de Pós-Graduação e Pesquisa em Administração (ENANPAD), 30., 2006, Salvador. Anais... Salvador: ANPAD, 2006.

BATISTA, I. Percepções dos Alunos de Negócios acerca de um Jogo de Empresas Online Considerando os seus Estilos de aprendizagem. Dissertação (Mestrado em Administração). São Paulo: FEA (USP), 2004.

BERGAMASCHI FILHO, E.; ALBUQUERQUE, A. Atitudes Tomadas Durante um Jogo de Empresas e seu Impacto na Tomada de Decisão: Estudo de Caso Aplicado em uma Turma de Contabilidade. In: Encontro de Ensino e Pesquisa em Administração e Contabilidade (ENEPQ), 2., 2009, Curitiba. Anais... Curitiba: ANPAD, 2009.

BOUZADA, M. (Org.). Jogando Logística no Brasil. Curitiba: CRV, 2011.

BOUZADA, M. Um jogo de Logística genuinamente brasileiro. Dissertação (Mestrado em Administração). Rio de Janeiro: COPPEAD (UFRJ), 2001.

FERNANDES, R. Um Novo Ambiente Interativo de Apredizagem: A Criação de um Simulador Orçamentário. Contabilidade Vista \& Revista, v.13, n.1, p. 9-30, abr 2002.

FERREIRA, J. Jogos de Empresas: modelo para aplicação prática no ensino de custos e administração do capital de giro em pequenas e médias empresas industriais. Dissertação (Mestrado em Engenharia de Produção). Florianópolis: UFSC, 2000.

FREITAS, C.; LOPES, P. Jogos De Empresas No Estudo Do Mercado De Capitais: Modelagem E Criação Do JMC. In: Seminários de Administração (SEMEAD), 11., 2008, São Paulo. Anais... São Paulo: FEA (USP), 2008.

FREITAS, S.; SANTOS, L. Jogos de Empresas: Um Estudo Exploratório sobre a Percepção e o Desempenho dos Alunos dos Cursos de Administração e Ciências Contábeis. In: Encontro da Associação Nacional de Pós-Graduação e Pesquisa em Administração (ENANPAD), 27., 2003, Atibaia. Anais... Atibaia: ANPAD, 2003.

GOLDSCHMIDT, P. Simulação e jogo de empresas. Revista de Administração de Empresas, 
v.17, n.3, pp.43-46. Rio de Janeiro: FGV, mai/jun1977.

GRAMIGNA, M. Jogos de empresa. São Paulo: Makron Books, 1993.

HEIN, A.; RABENSCHLAG, D. Modelagem De Um Jogo De Empresas Para O Ensino De Custos Na Graduação. In: Encontro Nacional De Engenharia De Produção (ENEGEP), 27., 2007, Foz do Iguaçu. Anais... Foz do Iguaçu: ABEPRO, 2007.

KNABBEN, B.; FERRARI, R. A simulação estratégica como instrumento de treinamento gerencial. Revista de Negócios, v. 1, p. 31-37. Blumenau (SC), 1997.

KOPITTKE, B. Simulação empresarial: faça seu jogo. In: Encontro da Associação Nacional de Pós-Graduação e Pesquisa em Administração (ENANPAD), 12., 1989, Belo Horizonte. Anais... Belo Horizonte: ANPAD, 1989.

LI, E.; BAILLIE, A. Mixing case method with business game: student evaluations. Simulation \& Gaming, v. 24, n. 3, pp. 336-355, sep 1993.

MIYASHITA, R. Elaboração e uso de um jogo de Logística. Dissertação (Mestrado em Administração). Rio de Janeiro: COPPEAD (UFRJ), 1997.

MOTTA, G.; MELO, D.; PAIXÃO, R. O Papel do Envolvimento do Aluno no Aprendizado com Jogos de Empresas. In: Encontro de Ensino e Pesquisa em Administração e Contabilidade (ENEPQ), 2., 2009, Curitiba. Anais... Curitiba: ANPAD, 2009.

MOTTA, G.; PAIXÃO, R.; MELO, D. A Aprendizagem de Estratégia Empresarial por meio dos Jogos de Empresas: o Discurso Coletivo de Alunos. In: Encontro de Estudos em Estratégia (3Es), 4., 2009, Recife. Anais... Recife: ANPAD, 2009.

MURITIBA, P.; SAUAIA, A.; MURITIBA, S. Comprometimento dos Alunos com os Métodos de Aprendizagem: Aulas Expositivas vs. Jogos de Empresas. In: Seminários de Administração (SEMEAD), 9., 2006, São Paulo. Anais... São Paulo: FEA (USP), 2006.

NAGAMATSU, F.; FEDICHINA, M.; GOZZI, S.; BOLDRIN, V. A aplicação do jogo de empresas no desenvolvimento gerencial: um estudo aplicado em cursos de graduação e pós-graduação (nível latu sensu). In: Seminários de Administração (SEMEAD), 9., 2006, São Paulo. Anais... São Paulo: FEA (USP), 2006.

OLIVEIRA, M.; SAUAIA, A. Percepção Docente para Aprendizagem Vivencial: um Estudo dos Benefícios dos Jogos de Empresas no Desenvolvimento de Competências Gerenciais. In: Encontro de Ensino e Pesquisa em Administração e Contabilidade (ENEPQ), 2., 2009, Curitiba. Anais... Curitiba: ANPAD, 2009.

PEIXOTO, R.; VELOSO, E.; LOPES, J. Fragilidades na Mensuração de Aprendizagem em Jogos de Empresas: uma reflexão. In: Encontro da Associação Nacional de Pós-Graduação e Pesquisa em Administração (ENANPAD), 27., 2003, Atibaia. Anais... Atibaia: ANPAD, 2003.

PEREIRA, I.; SANTOS, L.; RECH, I. A Interdisciplinaridade no Ensino Superior da Contabilidade no Brasil: Um Estudo Empírico da Percepção dos Egressos. In: Encontro da Associação Nacional de Pós-Graduação e Pesquisa em Administração (ENANPAD), 32., 2008, Rio de Janeiro. Anais... Rio de Janeiro: ANPAD, 2008..

RANDEL, J.; MORRIS, B.; WETZEL, C.; WHITEHILL, D. The effectiveness of games for educational purpose: a review of recent research. Simulation \& Gaming, v. 23, n. 3, pp-221276, 1992. 
ROCHA, L. Jogos de Empresa: Desenvolvimento de um Modelo para Aplicação no Ensino de Custos Industriais. Dissertação (Mestrado em Engenharia de Produção). Florianópolis: UFSC, 1997.

RODRIGUES, L.; RISCARROLI, V. O valor pedagógico de Jogos de Empresas. In: Encontro Nacional dos Cursos de Graduação em Administração (ENANGRAD), 12., São Paulo. Anais... São Paulo: ANGRAD, 2001.

ROSAS, A. Criação de um simulador educacional para empreendedores: simulando novos negócios B2B de base tecnológica. Tese (Doutorado em Administração). São Paulo: FEA (USP), 2009.

ROSAS, A.; SAUAIA, A. Jogos de Empresa na educação superior no Brasil. In: Encontro da Associação Nacional de Pós-Graduação e Pesquisa em Administração (ENANPAD), 30., 2006, Salvador. Anais... Salvador: ANPAD, 2006.

SAUAIA, A. Jogos de Empresas: tecnologia e aplicação. Dissertação (Mestrado em Administração). São Paulo: FEA (USP), 1989.

SAUAIA, A. Satisfação e Aprendizagem em Jogos de Empresas: Contribuições para a Educação Gerencial. Tese (Doutorado em Administração). São Paulo: FEA (USP), 1995.

SCHAFRANSKI, A. Jogos de Gestão da Produção: desenvolvimento e validação. Tese (Doutorado em Engenharia de Produção e Sistemas). Florianópolis: Programa de Pósgraduação em Engenharia de Produção e Sistemas (UFSC), 2002.

SILVA, M.; SAUAIA, A. Gestão de Marketing e Lucratividade: Um Estudo Com Jogos de Empresas. In: Seminários de Administração (SEMEAD), 11., 2008, São Paulo. Anais... São Paulo: FEA (USP), 2008.

STAHL, L.; LOPES, P. Estratégias de Avaliação para Jogos de Empresas Gerais: avaliando Desempenho ou Aprendizagem. In: Encontro da Associação Nacional de Pós-Graduação e Pesquisa em Administração (ENANPAD), 28., 2004, Curitiba. Anais... Curitiba: ANPAD, 2004.

VASCONCELLOS, E.; MATTAR, F. Avaliação do ensino de Administração: modelo conceitual e aplicação. In: Seminários de Administração (SEMEAD), 3., 1998, São Paulo. Anais... São Paulo: FEA (USP), 1998.

VICENTE, P. Jogos de Empresas. São Paulo: Makron Books, 2001.

VICENTE, P. O uso de simulação como metodologia de pesquisa em ciências sociais. Cadernos EBAPE.BR, v. 3, n. 1, p. 1-9, Mar 2005.

WOLFE, J.; LUETHGE, D. The impact of involvement on performance in business simulations: an examination of Goosen's "know little" decision-making thesis. Journal of Education for Business, Nov/Dec 2003. 